\title{
Patients on Dmards Undertaking Orthopaedic Procedures: Do We Discontinue The Drugs? Review of Current Literature
}

\author{
Karuppiah $\mathrm{SV}^{*}$ and Stavrou $\mathbf{P}$ \\ Department of Trauma and Orthopaedic Surgery, Flinders Medical Centre, South Australia
}

Submission: May 05, 2018; Published: May 16, 2018

*Corresponding author: Karuppiah SV, Department of Trauma and Orthopaedic Surgery, Flinders Medical Centre, Flinders Bedford Park, 5042 Drive, South Australia, Email: saravanavail@gmail.com

\section{Introduction}

The prevalence of Rheumatoid Arthritis (RA) is believed to range from 0.5 to $1.0 \%$ in the general population worldwide [1]. A small group of patients would require surgical management and these patients can be challenging. These is a cohort of patients requiring significant consideration before undertaking surgical treatment as they have a higher risk of complications during the peri operative period including surgical site wound infection (SSI) and delayed wound healing (DWH) [2].

The medical management of Rheumatoid arthritis has undergone various changes over the years. Currently Management of this disease is primarily with drugs that modify the inflammatory condition - Disease modifying anti-rheumatic drugs (DMARDS). Disease-modifying antirheumatic drugs (DMARDs) are a category of otherwise unrelated drugs defined by their use in rheumatoid arthritis to slow down disease progression. The term is often used in contrast to nonsteroidal anti-inflammatory drug (which refers to agents that treat the inflammation but not the underlying cause) and steroids (which diminishes the immune response but are insufficient to slow down the progression of the disease). These drugs are now named as a group of non biological or conventional synthetic drugs (csDMARDs) and include methotrexate, penicillamine, azathioprine, leflunamide, sulfasalazine, hydroxychloroquine, and gold.

Currently newer drugs have made significant difference to the management of this disease and markedly changed the functional status of patients with RA. This has opened to new challenges for surgeons as these drugs have a potential risk of compromising surgical outcome. The newer drugs - biological disease modifying antirheumatic drugs (bDMARDS) such as antiTNF- $\alpha$ inhibitors (adalimumab, atanercept, golimumab and infliximab), T cell costimulation inhibitor (abatacept), anti-B cell agent (rituximab) and the interleukin (IL)-6 receptor (IL-6R)blocking monoclonal antibody (tocilizumab), as well as the IL-1 inhibitor (anakinra) potentially modify the immune response. This potentially has been believed to contribute to an increase in SSI and defective wound healing.
Although logically stopping these drugs would reduce the surgical risk but has the potential for flare up of the rheumatoid disease leading to other medical issues [3]. Over the years recommendations and guidelines have been produced and consensus is now slowly developing on how to manage these patients pre and post operatively.

\section{Changing Paradigm Shift}

From time to time articles have been published highlighting the potential risk peri operative risk of patients on antirheumatic drugs and undergoing orthopaedic procedures. Methotrexate (MTX) is the most studied DMARD in RA patients undergoing surgery. Results of initial studies suggested an increased risk of infection when metho trexate was continued perioperatively. In 1991, Bridges et al followed by Carpenter et al in 1996 reported higher incidence of infection in patients with continued methotrexate undergoing orthopaedic procedures $[4,5]$. These studies were small but recommended discontinuing of the drug for routine orthopaedic procedures. Based on these reports, it was recommended to temporarily discontinue methotrexate around the time of surgery.

Subsequent studies including Murata et al. [6] and Grennan et al. [7] RCTs involving a large number of patients clearly showed continuation of MTX did not have a higher risk of peri operative infection. Pieringer et al. [8] review article recommended that discontinuation of MTX was not necessary during the perioperative period. The data to recommend use of leflunamide was insufficient, however, given its long half live and the availability of only limited data, it can be continued during the peri-operative period. The data about hydroxychloroquine was insufficient and they made no recommendations for it. A few studies have described the role of sulfasalazine, however, none of them were suggested of any potential risk of wound complication. They suggested that aspirin and other NSAIDs should be discontinued 4-5 half lives before the procedure to prevent anti-platelet effect. Patients with chronic glucocorticoid therapy and suppressed pituitary-adrenal axis need glucocorticoid supplementation. 
Lastly, anti-TNF- $\alpha$ agents should be discontinued for two weeks before surgery. There was no data on other biological agents.

\section{Current Literature on Bdmard}

One of the current interests in relation to the use of bDMARDs is the perioperative discontinuation of these drugs due to increased the risk of SSI and DWH it may be preferable to stop them prior to surgery. Recent guidelines recommend the same and some drugs require a tighter duration of drug free period pre operatively and significant consideration before they are restarted. However, this maybe controversial in some published studies $[9,10]$.

In a review article Mushtaq et al. [11] suggested that based on the minimal evidence available the decision on whether to continue or discontinue biological DMARDs agents, should be guided by balancing their potential risk of infection and disease flare-up. Secondly, for proper rehabilitation, medical control of the disease should be optimized as much as possible before surgery. They concluded that biological agents should be withheld for at least two half-life perioperatively until the wound heals. They recommended strict minimization of concomitant risk factors and vigilant monitoring for postoperative infection and wound complication in patients with the disease that is difficult to keep under control and in whom withholding of medication may not be possible. Similarly, in 2011 in a review article Keith mentioned that MTX can be continued during the perioperative period and biological agents should be discontinued. Reeves et al. [12] described complications of foot and ankle surgery in rheumatoid arthritis patients but only included a few studies in the review article [13-17]. Based upon that they recommended continuous use of all the antirheumatoid drugs (including biological) during perioperative period.

Amore recent article by Ito et al. [18] published a review of over 10 articles including 4,187 patients comparing wound complication risk of patients on csDMARDs vs. bDMARDSs. All patients on bDMARDs had drugs stopped prior to surgery, as per the Japan College of Rheumatology, reported on SSI and DWH. Data analysis in this study showed overall incidence of SSI was $0-20.8 \%$ in patients with bDMARDs and $0-5.4 \%$ in csDMARDs or any other drugs. The incidence of SSI was 2.1 to $20.8 \%$ in large joint surgery compared to $1.0-4.6 \%$ in bDMARD groups. Their meta-analysis showed a relative risk of bDMARDs was 2.03 with $95 \%$ CI of 1.4o-2.96 making this group marginally higher risk especially in cases of large joint surgery. Interestingly this article showed there was no difference in surgical wound healing (DWH) with both groups having similar risk of $0.5 .4 \%$ in bDMARDs and $0-6.8 \%$ in csDMARDs.

\section{Recommendations From Professional Organisations}

Several recognised institutions around the world have produced guidelines for perioperative management of rheumatoid patients on DMARD. These recommendations have been modified in keeping with published literature.
American College of Rheumatology (ACR) guidelines 2008 recommended that biologic agents should not be used during the perioperative period, for at least 1 week prior to and 1 week after surgery. It was recommended that this decision should be further tempered by the pharmacokinetic properties of a given biologic agent (e.g., longer periods of time off therapy may be appropriate when using agents with longer half-lives), and the type of surgery. The panel articulated less concern for withholding therapy for patients undergoing minor surgeries with a low risk of infection (e.g., cataract operations). The college reported lack of consistent evidence and yielded no recommendation regarding the use of nonbiologic DMARDs during the perioperative period [19].

British Society for Rheumatology guidelines 2010, recommend withholding of anti-TNF- $\alpha$ agents for 2-4 weeks prior to surgery. The therapy can be restarted once the wound is healed. It is recommended that patients who undergo artificial joint replacement surgery, e.g., knee or hip artificial joint, should be followed-up care- fully over a period of 6 months to ensure lack of infection [20]. Japan College of Rheumatology most revised guidelines 2013, have suggest discontinuing bDMARD, tumor necrosis factor (TNF) blockers should be withheld for 2 to 4 weeks before undergoing surgical procedures and recommend 2 to 4 weeks for etanercept (ETN) and adalimumab (ADA) or 4 weeks for infliximab (IFX) because of its long half-life. The guidelines for tocilizumab (TCZ) I still not clear [21,22].

Other Rheumatology societies in Europe including the French National Society and EULAR (European League Against Rheumatism) have drawn similar guidelines [23].

\section{Discussion}

Several studies have reported that perioperative adverse events, especially post- operative infection, might increase in RA patients under TNF- $\alpha$ blockade therapy. It is advised that surgery should be delayed until a sufficient time had elapsed from the last administration of TNF- $\alpha$ antagonists, taking into consideration the biological half-life of the drugs (infliximab: 7.7-9.5 days, etanercept: $102 \pm 30$ h) [23,24].

The most serious concern would be the effect of stopping these drugs would lead to flare up of the rheumatoid arthritis disease activity and there should be a surgical risk balance analysis before a decision is made [24]. After surgery, treatment with TNF- $\alpha$ antagonist could be resumed after complete healing of the surgical wound and in the absence of any infection [25-27]. So far studies on other bDMARDs are limited and inconclusive [9-17], [21-23].

\section{Conclusion}

Patients on bDMARDs have a relative high risk of SSI and this can be with be reduced with discontinuing the drugs in accordance to the drug half life with a minimum of 2-4 weeks prior to surgery and restart after wound has healed. Patients on 
csDMARDs can be continued on drugs during the perioperative period. Patients on bDMARD undergoing joint replacement surgery should be monitored closely for a period of 6 months after surgery for infection risk.

\section{References}

1. Gabriel SE (2001) The epidemiology of rheumatoid arthritis. Rheum Dis Clin North Am 27(2): 269-281.

2. Doran MF, Crowson CS, Pond GR, O'Fallon WM, Gabriel SE, et al. (2002) Frequency of infection in patients with rheumatoid arthritis compared with controls: a population-based study. Arthritis Rheum 46(9): 22872293.

3. Espinoza F, Le Blay P, Combe B (2017) Biologic Disease-modifying Antirheumatic Drug (bDMARD)-induced Neutropenia: A Registry from a Retrospective Cohort of Patients with Rheumatic Diseases Treated with 3 Classes of Intravenous bDMARD. J Rheumatol 44(6): 844-849.

4. Bridges SL, Lopez-Mendez A, Han KH (1991) Should methotrexate be discontinued before elective orthopedic surgery in patients with rheumatoid arthritis? J Rheumatol 18(7): 984-988.

5. Carpenter MT, West SG, Vogelgesang SA (1996) Postoperative joint infections in rheumatoid arthritis patients on methotrexate therapy. Orthopedics 19(3): 207-210.

6. Murata K, Yasuda T, Ito H (2006) Lack of increase in postoperative complications with low-dose methotrexate therapy in patients with rheumatoid arthritis undergoing elective orthopedic surgery. Mod Rheumatol 16(1): 14-19.

7. Grennan DM, Gray J, Loudon J (2001) Methotrexate and early postoperative complications in patients with rheumatoid arthritis undergoing elective orthopaedic surgery. Ann Rheum Dis 60(3): 214217.

8. Pieringer H, Stuby U, Biesenbach G (2007) Patients with rheumatoid arthritis undergoing surgery: how should we deal with antirheumatic treatment?. Semin Arthritis Rheum 36(5): 278-286.

9. Talwalkar SC, Grennan DM, Gray J, Johnson P, Hayton MJ, et al. (2005) Tumour necrosis factor alpha antagonists and early postoperative complications in patients with inflammatory joint disease undergoing elective orthopaedic surgery. Ann Rheum Dis 64(4): 650-651.

10. Wendling D, Balblanc J, Brousse A (2005) Surgery in patients receiving anti-tumour necrosis factor $\alpha$ treatment in rheumatoid arthritis: an observational study on 50 surgical procedures. Ann Rheum Dis 64(9): 1378-1379.

11. Mushtaq S, Goodman SM, Scanzello CR (2011) Perioperative management of biologic agents used in treatment of rheumatoid arthritis. Am J Ther 18(5): 426-434.

12. Keith MP (2011) Perspectives on rheumatoid arthritis for the orthopedic surgeon: overview of non-tumor necrosis factor biologic drugs and perioperative management. Am J Orthop (Belle Mead NJ) 40(12): E272-275.

13. Reeves CL, Peaden AJ, Shane AM (2010) The complications encountered with the rheumatoid surgical foot and ankle. Clin Podiatr Med Surg 27(2): 313-325.
14. Bibbo C, Anderson RB, Davis WH (2003) The influence of rheumatoid chemotherapy, age, and presence of rheumatoid nodules on postoperative complications in rheumatoid foot and ankle surgery: analysis of 725 procedures in 104 patients [corrected]. Foot Ankle Int 24(1): 40-44.

15. Bibbo C, Goldberg JW (2004) Infectious and healing complications after elective orthopaedic foot and ankle surgery during tumor necrosis factor-alpha inhibition therapy. Foot Ankle Int 25(5): 331-335.

16. den Broeder AA, Creemer MC, Fransen J, de Jong E, de Rooij DJ, et al. (2007) Risk factors for surgical site infections and other complications in elective surgery in patients with rheumatoid arthritis with special attention for anti-tumor necrosis factor: a large retrospective study.J Rheumatol 34(4): 689-695.

17. Grennan DM, Gray J, Loudon J (2001) Methotrexate and early postoperative complications in patients with rheumatoid arthritis undergoing elective orthopaedic surgery. Ann Rheum Dis 60(3): 214217.

18. Ito H, Kojima M, Nishida K, Matsushita I, Kojima T, et al. (2015) Postoperative complications in patients with rheumatoid arthritis using a biological agent - A systematic review and meta-analysis. Mod Rheumatol 25(5): 672-678.

19. Saag KG, Teng GG, Patkar NM (2008) American College of Rheumatology 2008 recommendations for the use of nonbiologic and biologic diseasemodifying antirheumatic drugs in rheumatoid arthritis. Arthritis Rheum 59(6): 762-784.

20. Ding T, Ledingham J, Luqmani R, Westlake S, Hyrich K, et al. (2010) BSR and BHPR rheumatoid arthritis guidelines on safety of anti-TNF therapies. Rheumatology 49(11): 2217-2219.

21. (2014) Guidelines of TNF inhibition therapy for rheumatoid arthritis (RA) (revised edition). Japan College of Rheumatology, Japan.

22. Koike R, Harigai M, Atsumi T, Amano K, Kawai S, et al. (2009) Japan College of Rheumatology 2009 guidelines for the use of tocilizumab, a humanized anti-interleukin-6 receptor monoclonal antibody, in rheumatoid arthritis. Mod Rheumatol 19(4): 351-357.

23. Howe CR, Gardner GC, Kadel NJ (2006) Perioperative medication management for the patient with rheumatoid arthritis. J Am Acad Orthop Surg 14(9): 544-551.

24. Bassetti S, Wasmer S, Hasler P (2005) Staphylococcus aureus in patients with rheumatoid arthritis under conventional and anti-tumor necrosis factor-alpha treatment. J Rheumatol 32(11): 2125-2129.

25. Jain A, Witbreuk M, Ball C, Nanchahal J (2002) Influence of steroids and methotrexate on wound complications after elective rheumatoid hand and wrist surgery. J Hand Surg Am 27(3): 449-455.

26. Henaux S, Ruyssen-Witrand A, Cantagrel A (2018) Risk of losing remission, low disease activity or radiographic progression in case of bDMARD discontinuation or tapering in rheumatoid arthritis: systematic analysis of the literature and meta-analysis. Annals of the Rheumatic Diseases 77: 515-522.

27. Goeb V, Ardizzone M, Arnaud L, Avouac J, Baillet A, et al. (2013) Recommendations for using TNFa antagonists and French Clinical Practice Guidelines endorsed by the French National Authority for Health. Joint Bone Spine 80(6): 574-581. 

CC This work is licensed under Creative BY

DOI: 10.19080/OROAJ.2018.11.555823
Your next submission with Juniper Publishers

will reach you the below assets

- Quality Editorial service

- Swift Peer Review

- Reprints availability

- E-prints Service

- Manuscript Podcast for convenient understanding

- Global attainment for your research

- Manuscript accessibility in different formats

( Pdf, E-pub, Full Text, Audio)

- Unceasing customer service

Track the below URL for one-step submission https://juniperpublishers.com/online-submission.php 